\title{
Persistence and costs with subcutaneous TNF-alpha inhibitors in immune-mediated rheumatic disease stratified by treatment line
}

This article was published in the following Dove Press journal:

Patient Preference and Adherence

16 January 2017

Number of times this article has been viewed

\author{
Axel Svedbom' \\ Johan Dalén' \\ Christopher M Black ${ }^{2}$ \\ Sumesh Kachroo ${ }^{2}$ \\ Mapi Group, Stockholm, Sweden; \\ Merck \& Co., Inc., Kenilworth, \\ $\mathrm{NJ}$, USA
}

Correspondence: Sumesh Kachroo Merck \& Co., Inc., I26 E. Lincoln Avenue, Rahway, NJ 07065, USA

$\mathrm{Tel}+\mathrm{I} 7325943847$

Fax + I 7325944910

Email sumesh.kachroo@merck.com
Objectives: The objectives of this study were to 1) describe and compare treatment persistence with first- and second-line subcutaneous tumor necrosis factor-alpha inhibitors (SC-TNFis) in patients with ankylosing spondylitis (AS), psoriatic arthritis (PsA), or rheumatoid arthritis (RA) (collectively immune-mediated rheumatic disease) in Sweden and 2) estimate and contrast health care costs in the two groups.

Methods: Patients who initiated their first or second SC-TNFi between May 62010 and December 122012 were identified from the Prescribed Drug Register. Persistence was estimated using survival analysis. Costs comprised specialized outpatient care, inpatient care, and medication. The persistence analysis was stratified by immune-mediated rheumatic disease diagnosis. Results: A total of 4,903 patients treated with their first and 845 patients treated with their second SC-TNFi were identified. Baseline characteristics differed between the two groups. Therefore, propensity score matching analysis was implemented. Second-line patients were matched to first-line patients, and four cohort pairs (AS, PsA, RA, and all diagnoses combined) were generated. Patients treated with their first SC-TNFi had statistically significant higher persistence than patients treated with their second SC-TNFi in PsA $(P=0.036)$, RA $(P=0.048)$, and all diagnoses combined $(P<0.001)$ but not in $\mathrm{AS}(P=0.741)$. Patients who were treated with their second SC-TNFi incurred higher costs than patients treated with their first SC-TNFi.

Conclusion: Overall, persistence to the first SC-TNFi was higher than persistence to the second SC-TNFi. Furthermore, the second SC-TNFi was associated with higher costs than the first SC-TNFi. Therefore, prescribing the SC-TNFi with the best long-term persistence first may be beneficial.

Keywords: persistence, rheumatic disease, biologics, rheumatoid arthritis, psoriatic arthritis, ankylosing spondylitis

\section{Introduction}

Ankylosing spondylitis (AS), psoriatic arthritis (PsA), and rheumatoid arthritis (RA) are chronic progressive immune-mediated rheumatic diseases (IMRDs) resulting in pain, deformity, and disability. ${ }^{1}$ IMRDs confer substantial humanistic and economic burden. ${ }^{2,3}$

The advent of biologic medications such as subcutaneous tumor necrosis factoralpha inhibitors (SC-TNFis) has transformed the management of IMRDs. ${ }^{4}$ Despite the benefits of biologic treatment, a significant proportion of patients with IMRDs fail to respond, lose response, or experience adverse events with first-line biologic treatment and may therefore require treatment with other biologics. ${ }^{5}$ 
A number of biologics, including SC-TNFis, have shown efficacy as second-line biologics in randomized controlled trials (RCTs), ${ }^{6-10}$ albeit no RCT has directly compared the efficacies of second-line biologic treatments. ${ }^{5}$ There are several important considerations for the choice of subsequent-line biologic treatment, including diagnosis, patient preferences, comorbidities, and serum status. ${ }^{5}$ For some patients, the best option may be treatment with sequential SC-TNFis. ${ }^{11-13}$

In IMRDs, treatment persistence can be used as a proxy for drug effectiveness, safety, and treatment satisfaction. ${ }^{14-16}$ Improved understanding of treatment persistence with sequential TNFis may aid clinicians and patients in decision making and improve accuracy of the expected treatment results. Furthermore, information on health care resource utilization (HCRU) cost consequences of sequential SC-TNFis may guide formularies and other payers on optimal funding decisions. From a payer perspective, high persistence may be considered to drive drug costs. Therefore, exploring total HCRU costs by treatment line may be important to describe the long-term cost implications of treatment persistence.

Numerous studies have described persistence to firstline SC-TNFi (first-line patients) or second-line SC-TNFis (second-line patients) in RA, PsA, and AS. However, only a handful of studies have compared persistence between firstand second-line patients in IMRDs, ${ }^{17-26}$ and to the best of our knowledge no study has compared and contrasted persistence in first- and second-line SC-TNFis among IMRDs. Similarly, to the best of our knowledge, no study has formally compared costs between first- and second-line SC-TNFis in IMRDs. Therefore, the aim of this retrospective administrative register study was to 1 ) describe and compare treatment persistence in first- and second-line SC-TNFi patients with IMRD in Sweden and 2) compare and contrast health care costs in first- and second-line SC-TNFi patients.

\section{Methods}

\section{Data sources}

This retrospective administrative register study was based on pseudonymized data from registers controlled by the National Board of Health and Welfare (NBHW), a Swedish governmental agency with population-based registers on health care accessible for research. All registers in this study have been used extensively in population-based health care research.

The Prescribed Drug Register (PDR) is a populationbased register with all prescribed medications dispensed in Swedish pharmacies from July 1, 2005. The register captures data on date of prescription and date of dispense, the specialty of the prescriber, anatomical therapeutical chemical code, defined daily dose, package size, and prescription instructions. The quality of the PDR is high, with the loss of patient information estimated to be $<1 \% .^{27}$

The National Patient Register (NPR) is a populationbased register on all inpatient and specialized outpatient care in Sweden. Data on inpatient care are captured from the 1960s, and data on outpatient care are available since 2001. By law, health care providers need to report data on visits to specialized outpatient and inpatient care to the NPR. The quality of the NPR is high, with more than $99 \%$ of all somatic (including surgery) and psychiatric hospital discharges registered. ${ }^{28}$

The Causes of Death Register (CDR) is a populationbased register on all deaths and their underlying causes in Sweden with data available since 1961. The proportion of missing values in CDR has been estimated at $\sim 1 \%$, and the register has been extensively used for registry research. $^{29}$

The NBHW performed the data extraction and pseudonymization of the data.

\section{Study design and patient selection}

All patients who filled at least one prescription of an SCTNFi (adalimumab, certolizumab pegol, etanercept, or golimumab) from 1 July, 2005 to January 1, 2013 were identified from the PDR. The study population was derived from the patients identified in the PDR based on inclusion and exclusion criteria designed to identify an adult population who filled a prescription for a new SC-TNFi for treatment of IMRD after the date (May 6, 2010) when all currently approved SC-TNFis were included in the Swedish reimbursement system. The included patients were classified by IMRD-diagnosis. Patients were defined as having either AS (ICD-10: M08.1, M45, M46.1, M46.8, and M46.9), PsA (ICD-10: L40.5, M07.0, M07.1, M07.2, and M07.3), or RA (ICD-10: M05.8, M05.9, M06.0 M06.9, and M12.3). Patients without a registered IMRD diagnosis were either defined as having "other arthritis" (ICD-10: M13) or were left undefined. Furthermore, patients were stratified into first- and second-line SC-TNFi cohorts based on prior SC-TNFi exposure. Patients who filled their first prescription for their first SC-TNFi were defined as first-line patients, whereas patients who filled their first prescription for their second SC-TNFi were defined as second-line patients. Patients were indexed at the first prescription of the relevant treatment course and patients were included in one group only. Details on inclusion 
and exclusion criteria and algorithms for stratification are provided in Supplementary material.

Figure 1 provides an overview of the study design. Baseline characteristics were measured during a period of 12 months before the index date. To ensure that patients had at least 12 months of HCRU follow-up data available, analyses were restricted to patients who were indexed prior to January 1, 2013. The reason for this was that HCRU data (with the exception for prescriptions) were available till December 31, 2013 only.

\section{Study outcomes}

In accordance with the ISPOR Medication Compliance and Persistence Work Group, persistence was defined as the "duration of time from initiation to discontinuation of therapy." 30 Persistence of the relevant treatment was measured from the date the patient filled the index prescription until the end of the duration of the last prescription. Durations of individual prescriptions were derived by multiplying a standard defined daily dose with the number of packages dispensed. Patients were allowed to have gaps between filled prescriptions, but were defined as nonpersistent if they had a gap exceeding 60 days (the "grace period"). The Swedish pharmacy system allows patients to refill prescriptions when two-thirds of the previous prescription has been consumed (eg, after two months of a three-month prescription) and patients may thus accumulate medication. Therefore, patients were permitted to accumulate medication from overlapping prescriptions and use it to cover future gaps between filled prescriptions.

HCRU and associated costs were captured in the PDR and NPR and comprised hospitalizations, outpatient specialist visits, and medication (stratified by treatment type: SC-TNFi, traditional disease-modifying antirheumatic drugs [DMARDs], and non-DMARDs). Costs of outpatient visits and hospitalizations were derived from DRG weights or, if a DRG weight had not been assigned, simple mean imputation. Medication costs were obtained from the PDR, which captures the costs of all dispensed prescriptions.

\section{Statistical analysis}

All study variables, including baseline covariates and outcome measures, were analyzed descriptively. Frequencies and percentages were provided for dichotomous variables. Means and standard deviations were provided for continuous variables. Results were presented for all included patients by index treatment line (first or second $\mathrm{SC}-\mathrm{TNFi}$ ). Comparisons of baseline characteristics and outcome measures between the study cohorts were also conducted. Appropriate tests (eg, $t$-test, Mann Whitney $U$-test,
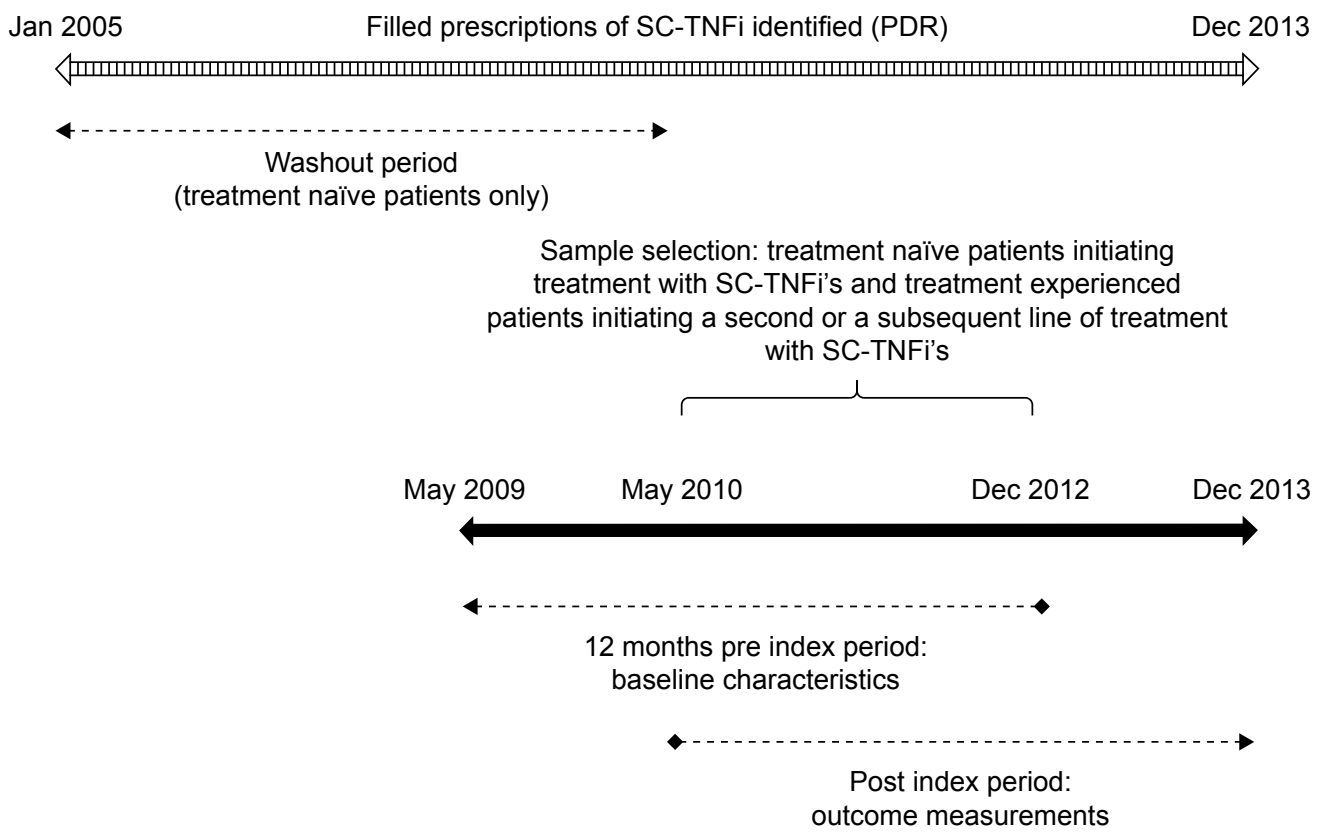

Figure I Study design: all patients who filled at least one prescription of an SC-TNFi from July I, 2005 to January I, 20I3 were identified from the PDR. Among the identified patients, only those who initiated their first or second SC-TNFi during the sample selection window (May 20I0 to December 20I2) were included in the analysis. Patients were indexed on the date of the first dispensed prescription of the relevant SC-TNFi. Furthermore, patients were required to have at least 12 months of observation time before and after the index date. Baseline characteristics were measured in the 12 months prior to indexation, and outcomes were measured for at least 12 months during follow-up.

Abbreviations: SC-TNFi, second-line subcutaneous tumor necrosis factor-alpha inhibitor; PDR, Prescribed Drug Register. 
chi-square test, Kruskal-Wallis test) were implemented based on the distribution of the relevant variable.

Time-to-event was derived using nonparametric survival analysis. Kaplan-Meier time-to-event (survival) functions were estimated with relevant treatment events as failure, and the proportions of patients having experienced an event at specific time points were derived from the failure rates. Estimates of persistence were derived directly from the survival functions.

To account for selection bias, comparisons of persistence between first- and second-line patients were conducted on propensity score matched (PSM) cohorts. In addition, cost comparisons were conducted on PSM cohorts of first and second line patients persistent at 6 months. PSM is a method that aims to reduce confounding bias by matching patients on the predicted probability of belonging to a certain group. ${ }^{31}$ Patients initiating a second-line SC-TNFi were defined as cases and matched on propensity score to patients who initiated a first-line SC-TNFi. A logit model was used to derive the propensity score in terms of predicted probability of initiating second-line SC-TNFi treatment given the baseline characteristics presented in Table 1. Pairs were matched using a greedy algorithm with 5 to 1 digit matching. As

Table I Patient characteristics at initiation of first- and second-line SC-TNFi

\begin{tabular}{|c|c|c|c|}
\hline & $\begin{array}{l}\text { First line } \\
N=4,903\end{array}$ & $\begin{array}{l}\text { Second line } \\
\mathbf{N}=845\end{array}$ & $P$-value \\
\hline Age (years) mean (SD) & $50.3(15.0)$ & $51.9(13.5)$ & 0.004 \\
\hline Female, n (\%) & $3,053(62.3)$ & $582(68.9)$ & $<0.001$ \\
\hline \multicolumn{4}{|l|}{ Index year } \\
\hline Indexed 2010, n (\%) & I, I94 (24.4) & $268(3 \mid .7)$ & \\
\hline Indexed 20II, n (\%) & 1,926 & $321(38.0)$ & \\
\hline Indexed 20I2, n (\%) & I,783 (36.4) & $256(30.3)$ & \\
\hline Index medication & & & $<0.001$ \\
\hline Adalimumab, n (\%) & I,823 (37.2) & $316(37.4)$ & \\
\hline Certolizumab pegol, n (\%) & $622(12.7)$ & $140(16.6)$ & \\
\hline Etanercept, n (\%) & I,704 (34.8) & $202(23.9)$ & \\
\hline Golimumab, n (\%) & $754(15.4)$ & $187(22.1)$ & \\
\hline IMRD diagnosis, n (\%) & & & 0.015 \\
\hline PsA & $898(18.3)$ & $146(17.3)$ & \\
\hline AS & I,029 (21.0) & $169(20.0)$ & \\
\hline RA & $2,563(52.3)$ & $484(57.3)$ & \\
\hline Other arthritis & $91(1.9)$ & $9(1.1)$ & \\
\hline Undefined & $322(6.6)$ & $37(4.4)$ & \\
\hline $\mathrm{CCl}$, mean $(\mathrm{SD})$ & $0.75(1.04)$ & $0.81(1.21)$ & 0.139 \\
\hline \multicolumn{4}{|l|}{ Co-medication } \\
\hline NSAIDs, n (\%) & $3,442(70.2)$ & $533(63.1)$ & $<0.001$ \\
\hline DMARDs, n (\%) & $3,849(78.5)$ & $526(62.2)$ & $<0.001$ \\
\hline Hospitalized, n (\%) & $932(19.0)$ & $199(23.6)$ & 0.002 \\
\hline
\end{tabular}

Abbreviations: SC-TNFi, second-line subcutaneous tumor necrosis factor-alpha inhibitor; SD, standard deviation; IMRD, immune-mediated rheumatic disease; PsA, psoriatic arthritis; AS, ankylosing spondylitis; RA, rheumatoid arthritis; $\mathrm{CCl}$, Charlson Comorbidity Index; NSAID, non-steroidal anti-inflammatory drug; DMARD, disease-modifying antirheumatic drug. suggested by Austin, Ho, Imai et al, balance across strata was evaluated using standardized differences in covariates pre- and post-matching rather than $P$-values. ${ }^{32-34}$ Rosenbaum and Rubin's suggested definition of balance was applied, ie, pre- and post-standardized differences below 0.1 were accepted. ${ }^{31}$

Differences in persistence between first- and secondline treatment cohorts were assessed using long-rank tests between PSM cohorts. Differences in persistence to first and second SC-TNFis across indications were assessed by comparing the median differences in time to nonpersistence between PSM matched pairs across the three indications; the statistical significance of the observed differences were tested using a Kruskal-Wallis test.

Statistical analyses were conducted using SAS software (SAS for XP PRO, Release 9.2 TS2 M3; SAS Institute Inc. Cary, NC, USA).

\section{Results}

The numbers of first- and second-line SC-TNFi patients fulfilling the inclusion/exclusion criteria were 4,903 and 845, respectively (Supplementary material). Compared to first-line patients, second-line patients were on average two years older, more likely to be hospitalized, but less likely to have concomitant treatment with either nonsteroidal anti-inflammatory drugs or nonbiologic DMARDs (Table 1). The distribution of IMRD diagnoses differed between the two groups $(P=0.015)$, with the largest absolute difference observed for the proportion of patients diagnosed with RA (5.0 percentage points, Table 1 ).

Given the systematic differences in patient characteristics between first- and second-line patients as already described, PSM analyses were implemented. Second-line patients were matched to first-line patients, and four successfully balanced cohort pairs, AS, PsA, RA, and all diagnoses combined, were generated with $169,146,460$, and 839 patients in each cohort, respectively (Table 2).

Comparing persistence rates between the PSM cohorts in the four strata showed that first-line patients had significantly higher persistence than second-line patients in PsA $(P=0.036)$, RA $(P=0.048)$, and all diagnoses $(P<0.001)$ but not in AS $(P=0.741)$ (Figure 2, Table S1). Median survival times expressed as months from initiation of index therapy for first- and second-line patients were estimated at 16.0 vs 11.1 in PsA; 12.4 vs 11.2 in AS; 12.6 vs 9.4 in RA; and 15.2 vs 9.6 in all patients. The difference in median time to non-persistence between patients on first and second-line therapy did not differ significantly across the three indications $(P=0.22)$. 
Table 2 Patient characteristics at initiation of first- and second-line SC-TNFi in propensity score matched cohorts

\begin{tabular}{|c|c|c|c|c|c|c|c|c|}
\hline & \multicolumn{2}{|l|}{ AS } & \multicolumn{2}{|l|}{ PsA } & \multicolumn{2}{|l|}{ RA } & \multicolumn{2}{|c|}{ All diagnoses } \\
\hline & $\begin{array}{l}\text { First line } \\
N=169\end{array}$ & $\begin{array}{l}\text { Second line } \\
N=169\end{array}$ & $\begin{array}{l}\text { First line } \\
N=146\end{array}$ & $\begin{array}{l}\text { Second line } \\
N=146\end{array}$ & $\begin{array}{l}\text { First line } \\
N=460\end{array}$ & $\begin{array}{l}\text { Second line } \\
N=460\end{array}$ & $\begin{array}{l}\text { First line } \\
N=839\end{array}$ & $\begin{array}{l}\text { Second line } \\
N=839\end{array}$ \\
\hline Age (years) mean (SD) & $47.7(12.6)$ & $47.1(12.0)$ & $53.6(10.9)$ & $52.4($ (I I.6) & $55.6(13.1)$ & $53.8(\mid 4.2)$ & $52.7(14.6)$ & $51.9(13.5)$ \\
\hline Female, n (\%) & $75(44.4)$ & $78(46.2)$ & $82(56.2)$ & $85(58.2)$ & 371 (80.7) & $370(80.4)$ & $592(70.6)$ & $577(68.8)$ \\
\hline \multicolumn{9}{|l|}{ Index year } \\
\hline Indexed 20I0, n (\%) & $48(28.4)$ & $50(29.6)$ & $4 I(28 . I)$ & $42(28.8)$ & $150(32.6)$ & $153(33.3)$ & $253(30.2)$ & $262(3 \mid .2)$ \\
\hline Indexed 201 I, n (\%) & $65(38.5)$ & $64(37.9)$ & $59(40.4)$ & $59(40.4)$ & $179(38.9)$ & $174(37.8)$ & $340(40.5)$ & $321(38.3)$ \\
\hline Indexed 2012, n (\%) & $56(33.1)$ & $55(32.5)$ & $46(31.5)$ & $45(30.8)$ & $|3|(28.5)$ & $133(28.9)$ & $246(29.3)$ & $256(30.5)$ \\
\hline $\mathrm{CCl}$, mean $(\mathrm{SD})$ & $0.21(0.82)$ & $0.14(0.62)$ & $0.23(0.92)$ & $0.21(0.73)$ & $1.22(0.88)$ & $1.26(1.12)$ & $0.85(1.07)$ & $0.81(1.21)$ \\
\hline \multicolumn{9}{|l|}{ Co-medication } \\
\hline NSAIDs, n (\%) & I $36(80.5)$ & II 4 (67.5) & $106(72.6)$ & $99(67.8)$ & $296(64.3)$ & $280(60.9)$ & 597 (7I.2) & $529(63.1)$ \\
\hline DMARDs, n (\%) & $69(40.8)$ & $66(39.1)$ & $98(67.1)$ & $96(65.8)$ & $335(72.8)$ & $335(72.8)$ & $539(64.2)$ & $526(62.7)$ \\
\hline Hospitalized, n (\%) & $34(20.1)$ & $36(21.3)$ & $24(16.4)$ & $22(15.1)$ & $|2|(26.3)$ & 119 (25.9) & $20 I(24.0)$ & $197(23.5)$ \\
\hline
\end{tabular}

Notes: No statistically significant difference was observed within each cohort pair. Mean standardized difference was below 0.1 within each cohort pair. Abbreviations: SC-TNFi, second-line subcutaneous tumor necrosis factor-alpha inhibitor; AS, ankylosing spondylitis; PsA, psoriatic arthritis; RA, rheumatoid arthritis; $\mathrm{SD}$, standard deviation; $\mathrm{CCl}$, Charlson Comorbidity Index; NSAID, non-steroidal anti-inflammatory drug; DMARD, disease-modifying antirheumatic drug.

In patients who remained persistent with treatment for at least six months, the annualized costs in patients treated with their first and second SC-TNFi were estimated at USD 10,898 and USD 11,328, respectively (difference: USD $860, P<0.001)$. During this period, mean SC-TNFis costs were numerically lower in second-line patients compared to first-line patients (USD 185, $P=0.095$ ). Excluding costs of SC-TNFis, there was no statistically significant difference in costs between first- and second-line patients in the six months preceding indexation (Table 3 ).
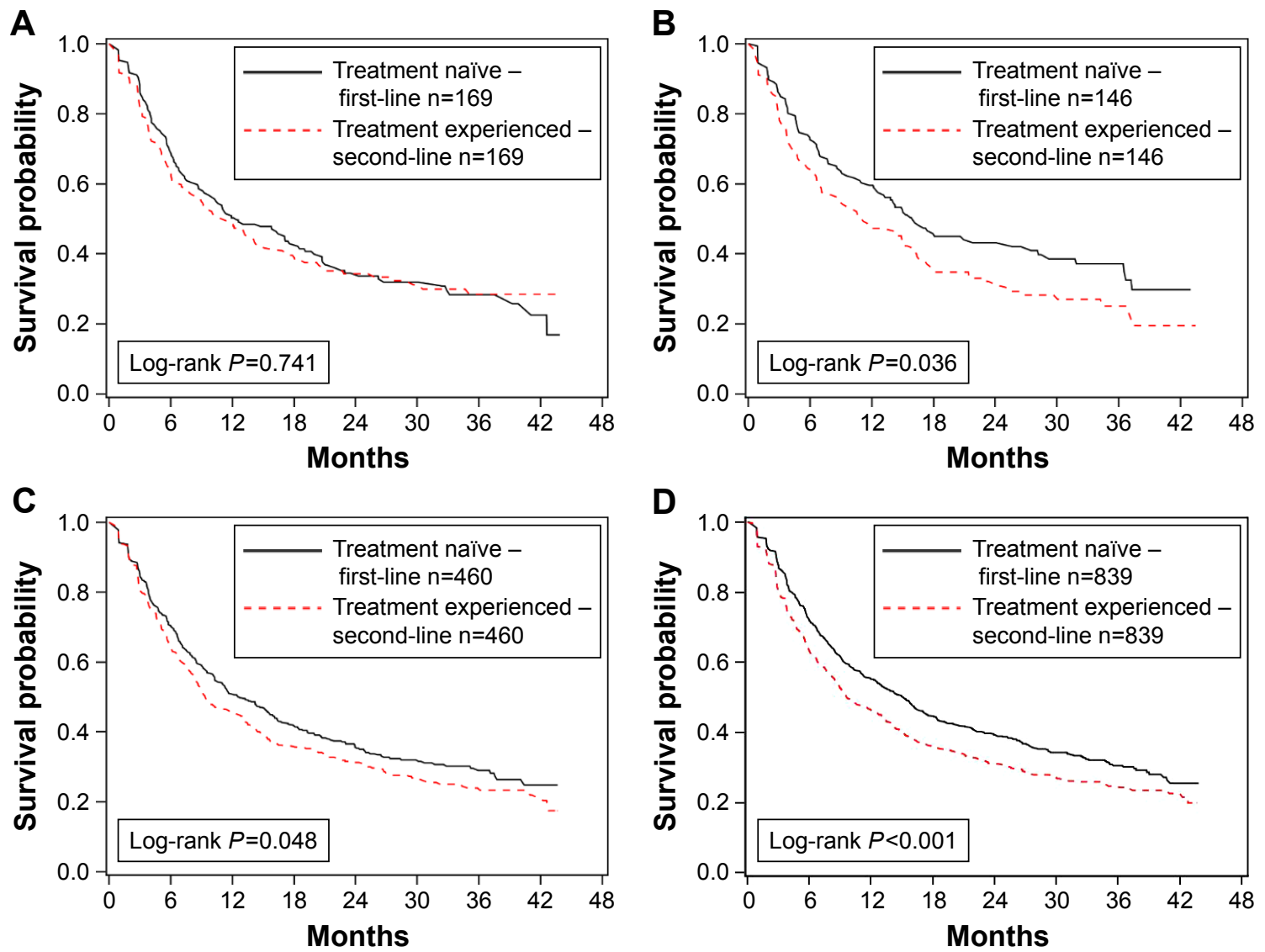

Figure 2 Propensity score matched analysis of persistence in first- and second-line SC-TNFi patients. (A) Analysis in patients with ankylosing spondylitis of (B) psoriatic arthritis, (C) rheumatoid arthritis, and (D) all patients.

Abbreviation: SC-TNFi, second-line subcutaneous tumor necrosis factor-alpha inhibitor. 
Table 3 Annualized health care resource utilization costs in first- and second-line SC-TNFi patients persistent at least six months

\begin{tabular}{|c|c|c|c|}
\hline & $\begin{array}{l}\text { First line, } \\
N=393\end{array}$ & $\begin{array}{l}\text { Second line, } \\
\mathbf{N}=393\end{array}$ & $P$-value \\
\hline \multicolumn{4}{|c|}{ HCRU costs 6 months prior to index date (USD) } \\
\hline Specialized outpatient care, mean (SD) & $1,315(1,036)$ & $1,342(1,292)$ & 0.36 \\
\hline Inpatient care, mean (SD) & $885(2,548)$ & $994(3,219)$ & 0.628 \\
\hline Non-DMARD medication, mean (SD) & $299(544)$ & $347(536)$ & 0.07 \\
\hline SC-TNFi treatment, mean (SD) & $0(0)$ & $3,968(3,448)$ & $<0.001$ \\
\hline Traditional DMARD treatment, mean (SD) & I0I (263) & $83(193)$ & 0.099 \\
\hline Total, mean (SD) & $2,600(3,183)$ & $6,734(4,940)$ & $<0.001$ \\
\hline \multicolumn{4}{|c|}{ HCRU costs 6 months post index date (USD) } \\
\hline Specialized outpatient care, mean (SD) & $862(703)$ & $\mathrm{I}, \mathrm{II} 6(\mathrm{I}, 067)$ & 0.005 \\
\hline Inpatient care, mean (SD) & $454(1,708)$ & $720(2,679)$ & 0.395 \\
\hline Non-DMARD medication, mean (SD) & $278(502)$ & $350(448)$ & $<0.001$ \\
\hline SC-TNFi treatment, mean (SD) & $9,233(1,80 I)$ & $9,048(2,026)$ & 0.095 \\
\hline Traditional DMARD treatment, mean (SD) & $70(188)$ & $94(236)$ & 0.62 \\
\hline Total, mean (SD) & $10,898(2,748)$ & $11,328(3,791)$ & $<0.001$ \\
\hline
\end{tabular}

Abbreviations: SC-TNFi, second-line subcutaneous tumor necrosis factor-alpha inhibitor; HCRU, Health Care Resource Utilization; SD, standard deviation; DMARD, disease-modifying antirheumatic drug.

\section{Discussion}

This study shows that persistence to the first SC-TNFi is higher than persistence to the second SC-TNFi in RA $(P=0.048)$ and PsA $(P=0.036)$, but not in $\operatorname{AS}(P=0.741)$. Across all patients, the difference in median time to nonpersistence persistence between first- and second-line patients was estimated at 5.6 months, with no statistically significant difference observed among the three indications $(P=0.22)$. Secondline patients incurred USD $860(P<0.001)$ more in annualized HCRU costs compared to first-line patients. The analyses were conducted using propensity score matching, adjusting for observable differences at treatment start.

Comparing absolute persistence estimates across studies is challenging given discrepancies in outcome definitions, patient populations, care settings, and statistical methodologies. ${ }^{30}$ However, the findings from this study supports the notion that first-line patients have higher persistence than second-line patients in $\mathrm{RA}^{17,21,23,26}$ and PsA. ${ }^{18,19,26}$ For AS, the impact of prior TNFi exposure on persistence differs among publications, ${ }^{20-22,24-26}$ and this study supports the notion that prior SC-TNFi exposure may not be associated with lower persistence. One potential reason for the differences in findings among the studies is the definition of AS. Saevarsdottir et al showed that persistence for AS, but not for other spondyloarthritides, was modified by prior biologic exposure, ${ }^{26}$ indicating that the delineation between AS and non-radiographic axial spondyloarthritis (nr-AxSpA) may be important; albeit in the absence of an ICD-10 code for nr-AxSpA, physicians may use M45.0-M45.9 (AS) $\operatorname{codes}^{35}$ for nr-AxSpA, resulting in that nr-AxSpA and AS cannot be distinguished in analysis of administrative data where patients are stratified by ICD-10 diagnosis. Another potential reason for the difference in findings between this study and the studies that found lower persistence in secondline patients compared to first-line patients with AS is that this study was conducted using PSM and thereby addressed potential selection bias, whereas the other studies did not adjust for such bias.

This study adds to the existing body of literature by having conducted analyses on administrative data, estimating persistence rates from refill compliance instead of patient reported data, thereby potentially reducing reporting bias. Furthermore, the study controls for differences in patients characteristics at treatment initiation, which to the best of our knowledge, has only been done in one previous study comparing persistence to SC-TNFi in first- and second-line patients. ${ }^{17}$

In terms of costs, the findings from this study indicated that second-line patients incur USD 840 higher costs per year than first-line patients. These results complement a recent US administrative claims data analysis that showed that patients who switched biologic incurred higher costs than patients who did not switch (USD 3,759 vs USD 2,343 per month; $P<0.05) .{ }^{36}$ Furthermore a recent Swedish study showed that patients who were nonpersistent incurred USD 1,730 higher costs per year compared to persistent patients. ${ }^{37}$ Given the findings in this study, it is conceivable that a proportion of the costs associated with nonpersistence to the first SCTNFi may be driven by the increased costs with second-line treatment.

The reason for the higher persistence and lower costs in first- compared to second-line patients cannot be directly determined from the data in this study; albeit given that 
the analyses were conducted using a PSM framework, the observed differences should be independent of sex, age, index year, treatment, co-medication, and hospitalization at treatment initiation. One potential reason is that patients who discontinue first-line SC-TNFi may experience a flare and therefore have high disease activity, a factor that has been associated with lower persistence. ${ }^{17}$ Another reason may relate to the production of antibodies that may evolve gradually over time. Regardless of reason, prescribing the $\mathrm{SC}-\mathrm{TNF}$ with the best first-line persistence first may generate better long-term outcomes given that the second SC-TNFi is associated with shorter persistence and higher costs than the first SC-TNFi. A recent systematic review and metaanalysis compared persistence to etanercept, adalimumab, and infliximab in RA patients, but noted a dearth of studies including more recently approved agents such as golimumab and certolizumab pegol. To the best of our knowledge, only one such study comparing all available SC-TNFis has been published. The study indicated that golimumab had significantly higher long-term persistence than adalimumab and etanercept and that there was a trend towards better persistence to golimumab compared to certolizumab pegol. ${ }^{37}$

Long-term real-world persistence data are particularly important given the external validity of long-term persistence estimates from extensions of RCTs. Patients in RCTs differ systematically from patients in clinical practice. ${ }^{38}$ In addition, patients in RCTs may change their behavior due to the fact that they participate in a study. ${ }^{38}$ These factors may compromise external validity, and it has been shown that adherence to therapy on average is higher in clinical trials than in clinical practice. ${ }^{39}$

The main strength of the study is the size and coverage of the data. The PDR captures more than $99 \%$ of all prescriptions of SC-TNFi in Sweden. ${ }^{40}$ Hence, the study includes virtually all patients who initiated a first- or second-line SC-TNFi in Sweden during the sample selection window (May 7, 2010 to December 31, 2012). Therefore, the study could identify a sufficient number of patients on first- and second-line SC-TNFi across different indications in spite of the relatively limited sample selection window. The study has a number of limitations. The study used administrative data and therefore persistence was estimated using prescription refills, whether the patients actually injected the medications or not could not be determined in the data. Another limiting aspect of administrative data is that clinician- and patient-reported outcomes such as Health Assessment Questionnaire, Disease Activity Score 28, or EuroQol 5 Dimensions are not available. Hence, effectiveness and reasons for discontinuation could not be determined directly. Limitations specific to this study include that the PDR does not record information on exact dosage and that the NPR only registers visits to outpatient specialists, resulting in that primary care and nurse visits are not captured in the data. Furthermore, out of pocket costs are not included in the study, albeit these should be limited reflecting that the Swedish government reimburses any costs for prescribed drugs exceeding SEK 1,100 (approximately USD 140) per year. Furthermore, infliximab is predominately administered during office visits in Sweden, resulting in that the drug is insufficiently captured in the PDR. ${ }^{40}$ Hence, some patients in the study may previously have been treated with infliximab. Finally, it should be noted that this study was conducted on Swedish administrative register data and the findings may not be generalizable or applicable to other settings.

There is a need for further research in this field. Firstly, real-world data comparing effectiveness and persistence among all currently available SC-TNFis would be valuable. Secondly, studies capturing additional cost categories could more precisely estimate cost consequences of first- and second-line SC-TNFi treatment. Finally, hybrid studies linking clinical registers to administrative data would allow for more accurate assessment of persistence, compliance, effectiveness, and costs than using either data type in isolation.

In conclusion, this study indicates that treatment with sequential SC-TNFis is beneficial, albeit on average persistence to the second SC-TNFi can be expected to be lower than persistence to the first SC-TNFi. Furthermore, the second SC-TNFi was associated with higher costs than the first SC-TNFi. Therefore, prescribing the SC-TNFi with the best long-term persistence first may be beneficial.

\section{Compliance with ethical standards Ethical approval}

All procedures performed in studies involving human participants were in accordance with the ethical standards of the institutional and/or national research committee and with the 1964 Helsinki declaration and its later amendments or comparable ethical standards. The study was granted an ethical permit by the Regional Ethical Review Board in Stockholm. The study was approved by the NBHW. For this type of study, formal consent is not required according to Swedish law (Lag [1998:543] om hälsodataregister).

\section{Disclosure}

This study was funded by Merck \& Co., Inc., Kenilworth, NJ USA. AS and JD were paid consultants to Merck through 
their employment at Mapi. Mapi have received funding from several pharmaceutical companies involved in the marketing of products for treatment of rheumatic disease. CMB and SK are employees of Merck \& Co., Inc., Kenilworth, NJ USA, and hold stock and options. The authors report no other conflicts of interest in this work.

\section{References}

1. Silman AJ, Hochberg MC. Epidemiology of the rheumatic diseases. New York, USA: Oxford University Press; 2001.

2. Huscher D, Merkesdal S, Thiele K, Zeidler H, Schneider M, Zink A; German Collaborative Arthritis Centres. Cost of illness in rheumatoid arthritis, ankylosing spondylitis, psoriatic arthritis and systemic lupus erythematosus in Germany. Ann Rheum Dis. 2006;65(9):1175-1183.

3. Salaffi F, Carotti M, Gasparini S, Intorcia M, Grassi W. The healthrelated quality of life in rheumatoid arthritis, ankylosing spondylitis, and psoriatic arthritis: a comparison with a selected sample of healthy people. Health Qual Life Outcomes. 2009;7:25.

4. Stevens Seth R, Chang Ting H. History of development of TNF inhibitors. Basel, Switzerland: Springer; 2006:9-22.

5. Navarro Coy NC, Brown S, Bosworth A, et al. The 'Switch' study protocol: a randomised-controlled trial of switching to an alternative tumour-necrosis factor (TNF)-inhibitor drug or abatacept or rituximab in patients with rheumatoid arthritis who have failed an initial TNFinhibitor drug. BMC Musculoskelet Disord. 2014;15:452.

6. Cohen SB, Emery P, Greenwald MW, et al. Rituximab for rheumatoid arthritis refractory to anti-tumor necrosis factor therapy: results of a multicenter, randomized, double-blind, placebo-controlled, phase III trial evaluating primary efficacy and safety at twenty-four weeks. Arthritis Rheum. 2006;54(9):2793-2806.

7. Emery P, Keystone E, Tony HP, et al. IL-6 receptor inhibition with tocilizumab improves treatment outcomes in patients with rheumatoid arthritis refractory to anti-tumour necrosis factor biologicals: results from a 24-week multicentre randomised placebo-controlled trial. Ann Rheum Dis. 2008;67(11):1516-1523.

8. Genovese MC, Becker J-C, Schiff M, et al. Abatacept for rheumatoid arthritis refractory to tumor necrosis factor $\alpha$ inhibition. NEngl J Med. 2005;353(11):1114-1123.

9. Smolen JS, Kay J, Doyle MK, et al. Golimumab in patients with active rheumatoid arthritis after treatment with tumour necrosis factor $\alpha$ inhibitors (GO-AFTER study): a multicentre, randomised, doubleblind, placebo-controlled, phase III trial. Lancet. 2009;374(9685): 210-221.

10. Weinblatt ME, Fleischmann R, Huizinga TW, et al. Efficacy and safety of certolizumab pegol in a broad population of patients with active rheumatoid arthritis: results from the REALISTIC phase IIIb study. Rheumatology. 2012;51(12):2204-2214.

11. Braun J, van den Berg R, Baraliakos X, et al. 2010 update of the ASAS/EULAR recommendations for the management of ankylosing spondylitis. Ann Rheum Dis. 2011;70(6):896-904.

12. Smolen JS, Landewé R, Breedveld FC, et al. EULAR recommendations for the management of rheumatoid arthritis with synthetic and biological disease-modifying antirheumatic drugs: 2013 update. Ann Rheum Dis. 2013;0:1-18.

13. Gossec L, Smolen JS, Ramiro S, et al. European League Against Rheumatism (EULAR) recommendations for the management of psoriatic arthritis with pharmacological therapies: 2015 update. Ann Rheum Dis. 2015. doi:10.1136/annrheumdis-2015-208337.

14. Aletaha D, Smolen JS. Effectiveness profiles and dose dependent retention of traditional disease modifying antirheumatic drugs for rheumatoid arthritis. An observational study. J Rheumatol. 2002;29(8): 1631-1638.
15. Fries JF. Effectiveness and toxicity considerations in outcome directed therapy in rheumatoid arthritis. J Rheumatol Suppl. 1996;44:102-106.

16. Pincus T, Marcum SB, Callahan LF. Longterm drug therapy for rheumatoid arthritis in seven rheumatology private practices: II. Second line drugs and prednisone. J Rheumatol. 1992;19(12):1885-1894.

17. Chatzidionysiou K, Kristensen LE, Eriksson J, Askling J, van Vollenhoven R; Group Artis. Effectiveness and survival-on-drug of certolizumab pegol in rheumatoid arthritis in clinical practice: results from the national Swedish register. Scand J Rheumatol. 2015;44(6): $431-437$.

18. Fagerli KM, Lie E, van der Heijde D, et al. Switching between TNF inhibitors in psoriatic arthritis: data from the NOR-DMARD study. Ann Rheum Dis. 2013;72:1840-1844.

19. Glintborg B, Østergaard M, Krogh NS, et al. Clinical response, drug survival, and predictors thereof among 548 patients with psoriatic arthritis who switched tumor necrosis factor $\alpha$ inhibitor therapy: results from the Danish Nationwide DANBIO Registry. Arthritis Rheum. 2013; 65(5):1213-1223

20. Glintborg B, Østergaard M, Krogh NS T, et al. Clinical response, drug survival and predictors thereof in 432 ankylosing spondylitis patients after switching tumour necrosis factor $\alpha$ inhibitor therapy: results from the Danish nationwide DANBIO registry. Ann Rheum Dis. 2013; 72(7):1149-1155.

21. Gomez-Reino JJ, Carmona L; Group BIOBADASER. Switching TNF antagonists in patients with chronic arthritis: an observational study of 488 patients over a four-year period. Arthritis Res Ther. 2006; $8(1): 1-7$.

22. Gulyas K, Bodnar N, Nagy Z, et al. Real-life experience with switching TNF- $\alpha$ inhibitors in ankylosing spondylitis. Eur J Health Econ. 2014; 15(1):93-100.

23. Hyrich KL, Lunt M, Watson KD, Symmons DP, Silman AJ. Outcomes after switching from one anti-tumor necrosis factor $\alpha$ agent to a second anti-tumor necrosis factor $\alpha$ agent in patients with rheumatoid arthritis: results from a large UK national cohort study. Arthritis Rheum. 2007; 56(1):13-20.

24. Lie E, van der Heijde D, Uhlig T, et al. Effectiveness of switching between TNF inhibitors in ankylosing spondylitis: data from the NORDMARD register. Ann Rheum Dis. 2011;70(1):157-163.

25. Rosales-Alexander JL, Aznar JB, Pérez-Vicente S, Magro-Checa C. Drug survival of anti-tumour necrosis factor $\alpha$ therapy in spondyloarthropathies: results from the Spanish emAR II Study. Rheumatology. 2015.

26. Saevarsdottir S, Santacatterina M, Turesson C, Forsblad H, Jacobsson L, Lindblad S. Clinical characteristics and outcome of golimumab treatment differs between bio-naive and patients previously exposed to biologicals. Nationwide results on rheumatoid arthritis (RA), psoriatic arthritis (PSA), ankylosing spondylitis (AS) and other spondyloarthritides (SPA). Arthritis Rheum. 2014;(66):S705.

27. Pharmaceuticals - statistics for 2014. The National Board of Health and Welfare (Socialstyrelsen). Available from: https://www.socialstyrelsen. se/Lists/Artikelkatalog/Attachments/19768/2015-3-17.pdf. Accessed August 20, 2015.

28. Ludvigsson JF, Andersson E, Ekbom A, et al. External review and validation of the Swedish national inpatient register. BMC Public Health. 2011;11:450.

29. The National Board of Health and Welfare (Socialstyrelsen). Causes of Death 2013. Available from: https://www.socialstyrelsen. se/Lists/Artikelkatalog/Attachments/19736/2015-2-42.pdf. Accessed August 20, 2015.

30. Cramer JA, Roy A, Burrell A, et al. Medication compliance and persistence: terminology and definitions. Value Health. 2008;11(1): 44- 47.

31. Rosenbaum PR, Rubin DB. Constructing a control group using multivariate matched sampling methods that incorporate the propensity score. American Statistician. 1985;39(1):33-38. 
32. Austin PC. Balance diagnostics for comparing the distribution of baseline covariates between treatment groups in propensity-score matched samples. Statistics Med. 2009;28(25):3083-3107.

33. Ho DE, Imai K, King G, Stuart EA. Matching as nonparametric preprocessing for reducing model dependence in parametric causal inference. Polit Anal. 2007;15(3):199-236.

34. Imai K, King G, Stuart EA. Misunderstandings between experimentalists and observationalists about causal inference. J R Stat Soc Ser A Stat Soc. 2008;171(2):481-502.

35. Deodhar A, Strand V, Kay J, Braun J. The term 'non-radiographic axial spondyloarthritis' is much more important to classify than to diagnose patients with axial spondyloarthritis. Ann Rheum Dis. 2016; 75(5):791-794.

36. Meissner B, Trivedi D, You M, Rosenblatt L. Switching of biologic disease modifying anti-rheumatic drugs in patients with rheumatoid arthritis in a real world setting. J Med Econ. 2014;17(4):259-265.
37. Dalén J, Svedbom A, Black CM, et al. Treatment persistence among patients with immune-mediated rheumatic disease newly treated with subcutaneous TNF-alpha inhibitors and costs associated with nonpersistence. Rheumatol Int. 2016:1-9.

38. Koncz T, Pentek M, Brodszky V, Ersek K, Orlewska E, Gulacsi L. Adherence to biologic DMARD therapies in rheumatoid arthritis. Expert Opin Biol Ther. 2010;10(9):1367-1378.

39. Osterberg L, Blaschke T. Adherence to medication. NEngl JMed. 2005; 353(5):487-497.

40. Neovius M, Sundstrom A, Simard J, et al. Small-area variations in sales of TNF inhibitors in Sweden between 2000 and 2009. Scand J Rheumatol. 2011;40(1):8-15. 


\section{Supplementary materials Inclusion/exclusion criteria}

For the first-line cohort, patients meeting the following inclusion criterion were selected for study inclusion:

- At least one dispensed prescription of the following second-line subcutaneous tumor necrosis factor-alpha (SC TNF-alpha) blocker during the sample selection window May 1, 2010 to December 31, 2012:

- Adalimumab

- Certolizumab pegol

- Etanercept

- Golimumab

Patients meeting the inclusion criteria were excluded from the cohort based on the following exclusion criteria:

○ Less than 18 years of age on index date

- A filled prescription for the index TNF-alpha inhibitor prior to May 6, 2010

- A registered treatment for a TNF-alpha inhibitor in an outpatient or inpatient setting

- Fewer than twelve months baseline and follow-up periods due to emigration, death, or end of data availability
- A second, third, or fourth line of second-line subcutaneous tumor necrosis factor-alpha inhibitors (SC-TNFis)

- A filled prescription of a SC-TNFi from:

- a department other than (1) rheumatology, (2) orthopedics, and (3) rehabilitation and

- a prescriber who was not specialized in rheumatology.

The implementation of the inclusion/exclusion criteria on the population are provided in the Figure S1.

For the second-line cohort, patients meeting the following inclusion criterion were selected for study inclusion:

- At least one dispensed prescription for two of the following SC TNF-alpha blockers, one before and one during the sample selection window May 1, 2010 to December 31, 2012:

- Adalimumab

- Certolizumab pegol

- Etanercept

- Golimumab

Patients meeting the inclusion criteria were excluded from the cohort based on the following exclusion criteria:

$\circ$ Less than 18 years of age on index date

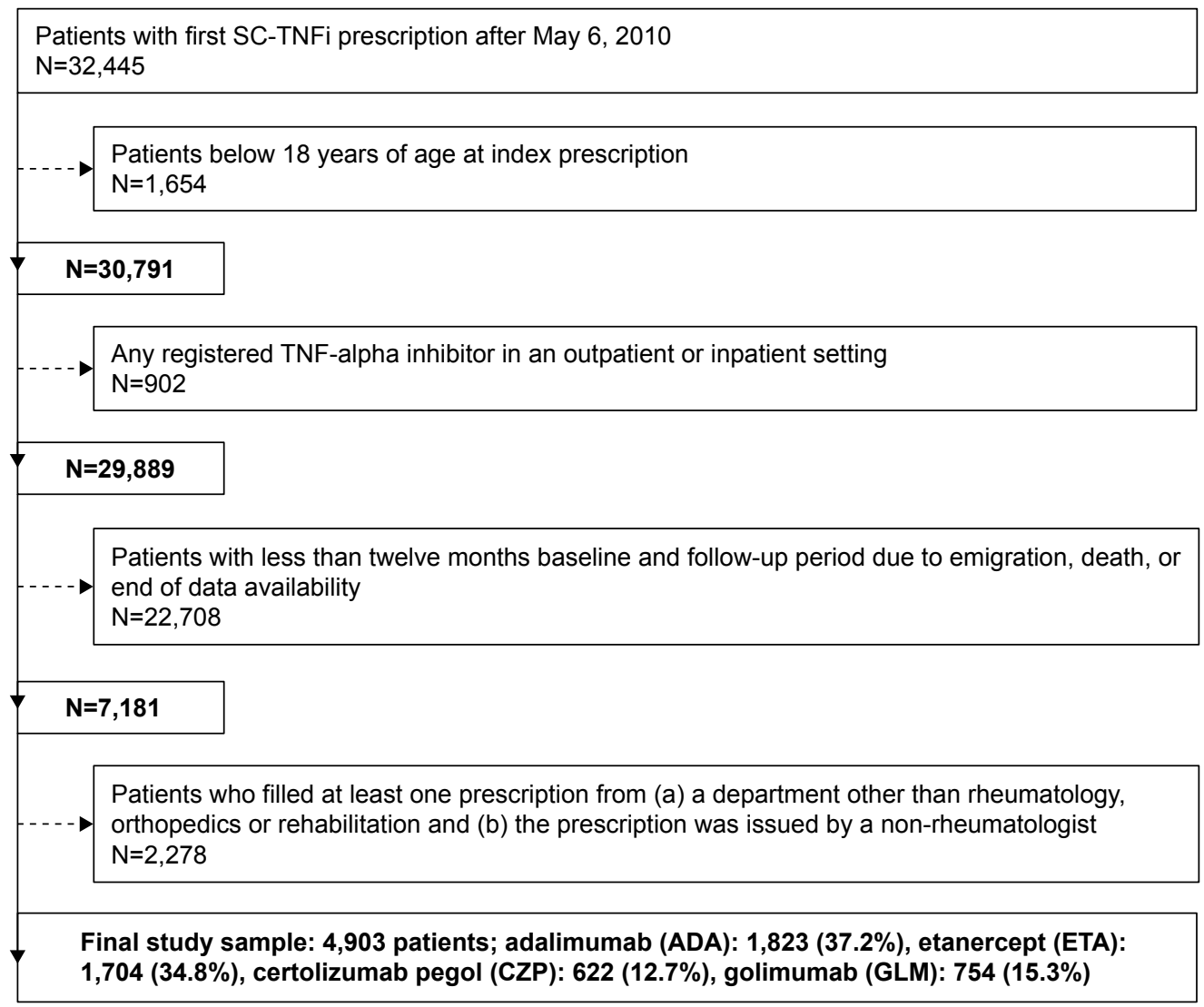

Figure SI Sequential sample selection first line patients.

Abbreviations: SC-TNFi, second-line subcutaneous tumor necrosis factor-alpha inhibitor; TNF, tumor necrosis factor. 


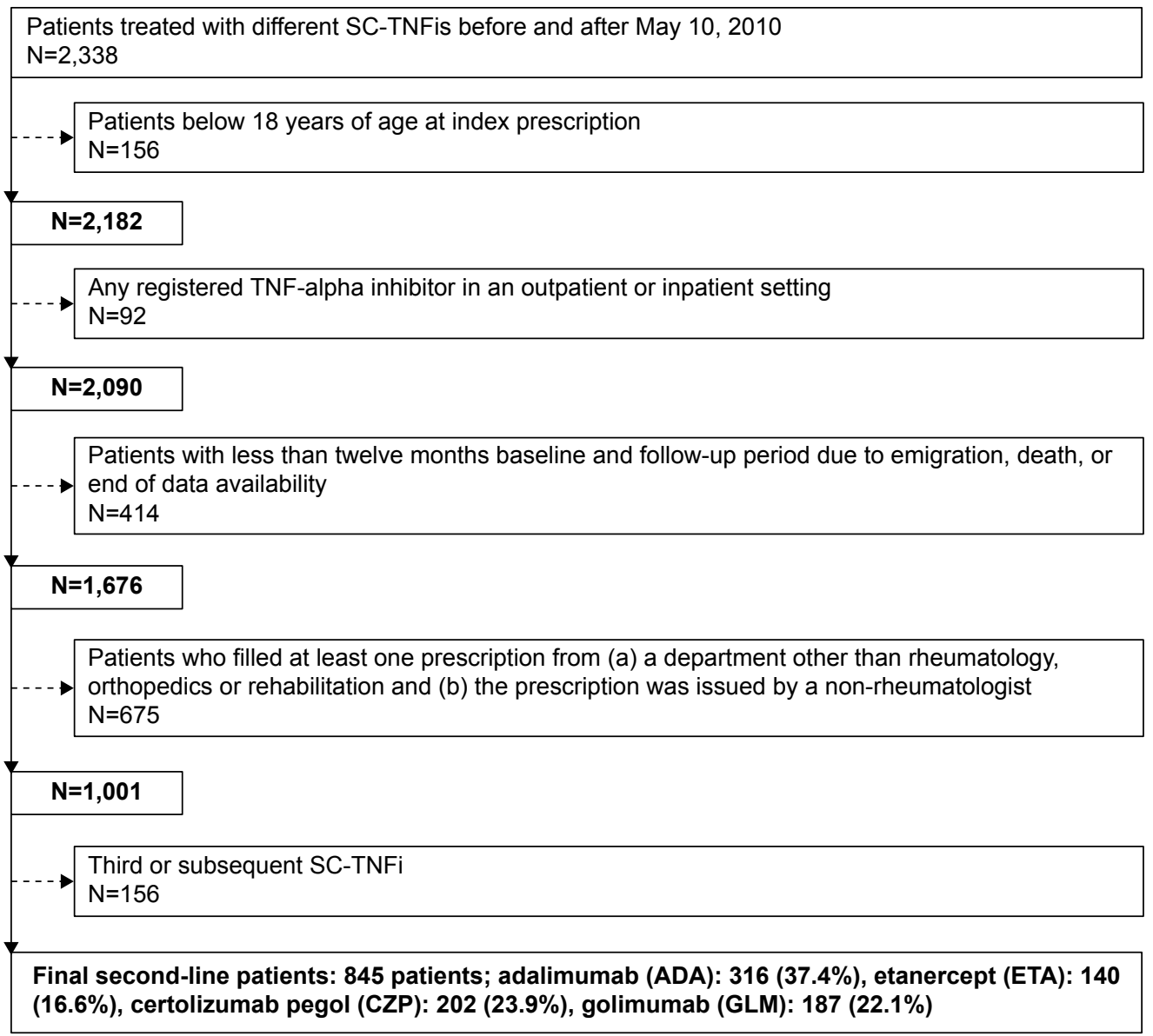

Figure S2 Sequential sample selection second line patients.

Abbreviations: SC-TNFi, second-line subcutaneous tumor necrosis factor-alpha inhibitor; TNF, tumor necrosis factor.

Table SI Life table for propensity score matched analysis of persistence in first- and second-line SC-TNFi patients with AS, PsA, RA, and all diagnoses

\begin{tabular}{|c|c|c|c|c|c|c|c|c|}
\hline & \multicolumn{2}{|l|}{ AS } & \multicolumn{2}{|l|}{ PsA } & \multicolumn{2}{|l|}{ RA } & \multicolumn{2}{|c|}{ All diagnoses } \\
\hline & $\begin{array}{l}\text { First line } \\
N=169\end{array}$ & $\begin{array}{l}\text { Second line } \\
N=169\end{array}$ & $\begin{array}{l}\text { First line } \\
N=146\end{array}$ & $\begin{array}{l}\text { Second line } \\
N=146\end{array}$ & $\begin{array}{l}\text { First line } \\
N=460\end{array}$ & $\begin{array}{l}\text { Second line } \\
N=460\end{array}$ & $\begin{array}{l}\text { First line } \\
N=839\end{array}$ & $\begin{array}{l}\text { Second line } \\
\mathbf{N}=839\end{array}$ \\
\hline Censored, n (\%) & $54(32.0)$ & $56(33.1)$ & $57(39.0)$ & $4 I(28 . I)$ & $152(33.0)$ & $128(27.8)$ & $297(35.4)$ & $239(28.5)$ \\
\hline Failed, n (\%) & $115(68.0)$ & $113(66.9)$ & $89(61.0)$ & $105(71.9)$ & $308(67.0)$ & $332(72.2)$ & $542(64.6)$ & $600(7 \mid .5)$ \\
\hline \multicolumn{9}{|c|}{ Survival time (months) } \\
\hline Median (K-M) & 12.4 & 11.2 & 16.0 & 11.1 & 12.6 & 9.4 & 15.2 & 9.6 \\
\hline $95 \% \mathrm{Cl}$ of median (K-M) & $9.3,18.4$ & $7.8,14.5$ & $12.4,27.5$ & $7.1,16.1$ & $10.5,15.6$ & $8.5,12.1$ & $13.0,16.4$ & $8.9,11.8$ \\
\hline QI, Q3 (K-M) & $5 . I, 4 I . I$ & 4.0, NE & $4.9, \mathrm{NE}$ & $3.7,37.1$ & $4.8,40.4$ & $4.3,34.4$ & 5.6, NE & $3.9,35.1$ \\
\hline Min, $\max$ & $0.9,43.9$ & $0.9,43.5$ & $0.9,43.0$ & $0.5,43.5$ & $0.9,43.7$ & $0.9,43.7$ & $0.1,43.8$ & $0.5,43.7$ \\
\hline \multicolumn{9}{|c|}{ K-M survival estimates, $n$ at risk, survival probability $(95 \% \mathrm{Cl})$} \\
\hline \multirow[t]{2}{*}{ I Month } & $n=161,0.95$ & $\mathrm{n}=155,0.92$ & $\mathrm{n}=138,0.95$ & $\mathrm{n}=|33,0.9|$ & $\mathrm{n}=433,0.94$ & $n=432,0.94$ & $\mathrm{n}=802,0.96$ & $\mathrm{n}=780,0.93$ \\
\hline & $(0.91,0.98)$ & $(0.86,0.95)$ & $(0.89,0.97)$ & $(0.85,0.95)$ & $(0.92,0.96)$ & $(0.91,0.96)$ & $(0.94,0.97)$ & $(0.91,0.95)$ \\
\hline \multirow[t]{2}{*}{3 Months } & $n=149,0.88$ & $\mathrm{n}=139,0.82$ & $n=126,0.86$ & $\mathrm{n}=116,0.79$ & $\mathrm{n}=393,0.85$ & $\mathrm{n}=375,0.82$ & $n=736,0.88$ & $\mathrm{n}=675,0.80$ \\
\hline & $(0.82,0.92)$ & $(0.76,0.87)$ & $(0.80,0.91)$ & $(0.72,0.85)$ & $(0.82,0.88)$ & $(0.78,0.85)$ & $(0.85,0.90)$ & $(0.78,0.83)$ \\
\hline \multirow[t]{2}{*}{6 Months } & $\mathrm{n}=117,0.69$ & $\mathrm{n}=107,0.63$ & $\mathrm{n}=107,0.73$ & $\mathrm{n}=94,0.64$ & $\mathrm{n}=325,0.71$ & $\mathrm{n}=295,0.64$ & $\mathrm{n}=605,0.72$ & $\mathrm{n}=532,0.63$ \\
\hline & $(0.62,0.76)$ & $(0.56,0.70)$ & $(0.65,0.80)$ & $(0.56,0.72)$ & $(0.66,0.75)$ & $(0.60,0.68)$ & $(0.69,0.75)$ & $(0.60,0.67)$ \\
\hline \multirow[t]{2}{*}{12 Months } & $\mathrm{n}=85,0.50$ & $\mathrm{n}=83,0.49$ & $\mathrm{n}=87,0.60$ & $\mathrm{n}=70,0.48$ & $\mathrm{n}=233,0.5 \mathrm{I}$ & $\mathrm{n}=210,0.46$ & $\mathrm{n}=46 \mathrm{I}, 0.55$ & $\mathrm{n}=389,0.46$ \\
\hline & $(0.43,0.58)$ & $(0.4 \mathrm{I}, 0.56)$ & $(0.5 \mathrm{I}, 0.67)$ & $(0.40,0.56)$ & $(0.46,0.55)$ & $(0.4 \mathrm{I}, 0.50)$ & $(0.52,0.59)$ & $(0.43,0.50)$ \\
\hline \multirow[t]{2}{*}{ I8 Months } & $\mathrm{n}=59,0.43$ & $\mathrm{n}=58,0.40$ & $n=59,0.46$ & $\mathrm{n}=47,0.36$ & $\mathrm{n}=167,0.42$ & $n=|4|, 0.36$ & $\mathrm{n}=325,0.45$ & $\mathrm{n}=26 \mathrm{I}, 0.36$ \\
\hline & $(0.35,0.50)$ & $(0.32,0.47)$ & $(0.37,0.54)$ & $(0.28,0.43)$ & $(0.37,0.46)$ & $(0.32,0.40)$ & $(0.4 I, 0.48)$ & $(0.33,0.39)$ \\
\hline
\end{tabular}

(Continued) 
Table SI (Continued)

\begin{tabular}{|c|c|c|c|c|c|c|c|c|}
\hline & \multicolumn{2}{|l|}{ AS } & \multicolumn{2}{|l|}{ PsA } & \multicolumn{2}{|l|}{ RA } & \multicolumn{2}{|c|}{ All diagnoses } \\
\hline & $\begin{array}{l}\text { First line } \\
\mathbf{N}=169\end{array}$ & $\begin{array}{l}\text { Second line } \\
N=169\end{array}$ & $\begin{array}{l}\text { First line } \\
N=146\end{array}$ & $\begin{array}{l}\text { Second line } \\
N=146\end{array}$ & $\begin{array}{l}\text { First line } \\
\mathbf{N}=460\end{array}$ & $\begin{array}{l}\text { Second line } \\
\mathbf{N}=460\end{array}$ & $\begin{array}{l}\text { First line } \\
\mathbf{N}=\mathbf{8 3 9}\end{array}$ & $\begin{array}{l}\text { Second line } \\
\mathbf{N}=839\end{array}$ \\
\hline \multirow[t]{2}{*}{24 Months } & $\mathrm{n}=42,0.35$ & $\mathrm{n}=40,0.34$ & $\mathrm{n}=42,0.43$ & $\mathrm{n}=34,0.32$ & $\mathrm{n}=\mathrm{I} \mid \mathrm{I}, 0.36$ & $\mathrm{n}=104,0.31$ & $n=239,0.39$ & $\mathrm{n}=|88,0.3|$ \\
\hline & $(0.27,0.42)$ & $(0.27,0.42)$ & $(0.35,0.5 \mathrm{I})$ & $(0.25,0.40)$ & $(0.31,0.40)$ & $(0.27,0.36)$ & $(0.36,0.43)$ & $(0.28,0.34)$ \\
\hline \multirow[t]{2}{*}{30 Months } & $n=30,0.32$ & $\mathrm{n}=26,0.31$ & $\mathrm{n}=32,0.39$ & $\mathrm{n}=23,0.28$ & $\mathrm{n}=76,0.32$ & $\mathrm{n}=62,0.26$ & $\mathrm{n}=165,0.34$ & $n=119,0.27$ \\
\hline & $(0.25,0.40)$ & $(0.24,0.39)$ & $(0.30,0.47)$ & $(0.21,0.36)$ & $(0.27,0.37)$ & $(0.22,0.31)$ & $(0.31,0.38)$ & $(0.24,0.30)$ \\
\hline \multirow[t]{2}{*}{36 Months } & $n=15,0.28$ & $\mathrm{n}=16,0.28$ & $\mathrm{n}=17,0.37$ & $\mathrm{n}=\mathrm{I} \mathrm{I}, 0.25$ & $\mathrm{n}=46,0.29$ & $\mathrm{n}=40,0.24$ & $\mathrm{n}=89,0.31$ & $\mathrm{n}=70,0.25$ \\
\hline & $(0.21,0.36)$ & $(0.21,0.36)$ & $(0.29,0.46)$ & $(0.17,0.33)$ & $(0.24,0.34)$ & $(0.20,0.29)$ & $(0.27,0.34)$ & $(0.21,0.28)$ \\
\hline \multirow[t]{2}{*}{42 Months } & $\mathrm{n}=7,0.23$ & $\mathrm{n}=5,0.28$ & $\mathrm{n}=3,0.30$ & $\mathrm{n}=2,0.20$ & $\mathrm{n}=14,0.25$ & $\mathrm{n}=14,0.22$ & $\mathrm{n}=27,0.25$ & $\mathrm{n}=22,0.23$ \\
\hline & $(0.14,0.33)$ & $(0.21,0.36)$ & $(0.20,0.40)$ & $(0.11,0.29)$ & $(0.19,0.31)$ & $(0.17,0.27)$ & $(0.21,0.30)$ & $(0.19,0.26)$ \\
\hline
\end{tabular}

Abbreviations: SC-TNFi, second-line subcutaneous tumor necrosis factor-alpha inhibitor; AS, ankylosing spondylitis; PsA, psoriatic arthritis; RA, rheumatoid arthritis; $\mathrm{Cl}$, confidence interval; $\mathrm{NE}$, non-estimatable.

- A filled prescription for the index TNF-alpha inhibitor prior to May 62010

- A registered treatment for a TNF-alpha inhibitor in an outpatient or inpatient setting

○ Fewer than twelve months baseline and follow-up periods due to emigration, death, or end of data availability

- A third or a fourth line of SC-TNFis
- A filled prescription of a SC-TNFi from:

- a department other than (a) rheumatology, (b) orthopedics, and (c) rehabilitation and

- a prescriber was not-specialized in rheumatology

○ Third or subsequent SC-TNFi.

The implementation of the inclusion/exclusion criteria on the population are provided in Figure S2.

\section{Publish your work in this journal}

Patient Preference and Adherence is an international, peer-reviewed, open access journal that focuses on the growing importance of patient preference and adherence throughout the therapeutic continuum. Patient satisfaction, acceptability, quality of life, compliance, persistence and their role in developing new therapeutic modalities and compounds to optimize clinical outcomes for existing disease states are major areas of interest for the journal. This journal has been accepted for indexing on PubMed Central. The manuscript management system is completely online and includes a very quick and fair peer-review system, which is all easy to use. Visit http://www. dovepress.com/testimonials.php to read real quotes from published authors. 